\title{
Hydrological hazards in Vhembe district in Limpopo Province, South Africa
}

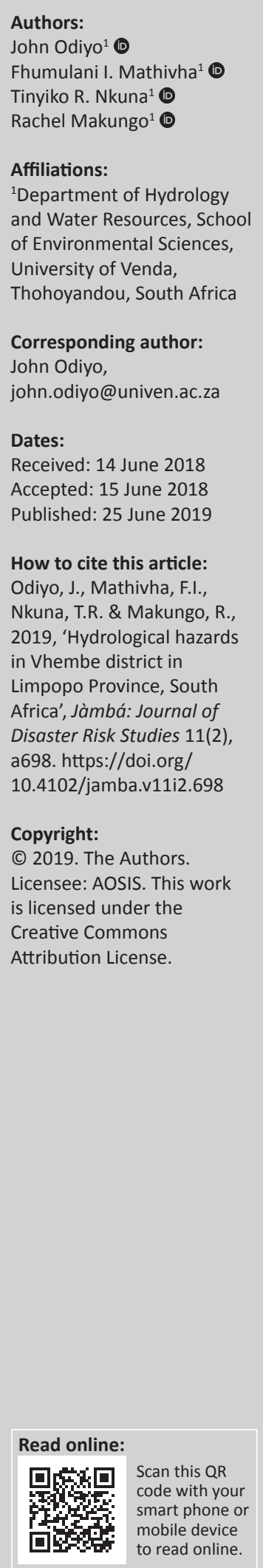

This study determined the risks associated with hydrological hazards and vulnerabilities to communities in Vhembe District Municipality, Limpopo province. Risk and vulnerability contribute to poverty, loss of lives and property, environmental and infrastructural destruction, food insecurity and unavailability of water resources. Streamflow and rainfall data were analysed using Log-Pearson Type III distribution and Standardised Precipitation Index (SPI), respectively, to identify return periods and probabilities of occurrence of floods and droughts. Mann-Kendall test was applied to identify trends of floods and droughts. Risk ratings were used to determine risks and vulnerabilities associated with floods and droughts. Standardised Precipitation Index analysis showed that a mild dryness condition dominated dry years in all stations with a range of $22.4 \%$ to $59.2 \%$ of the years falling within this category. Twenty-five per cent and $75 \%$ of rainfall stations depicted downward and upward trends, respectively. Equal number of streamflow stations depicted downward and upward trends. Results generally showed that flood events with return periods of 50, 100 and 200 years are mostly associated with significant and catastrophic consequence levels. This demonstrated high risk and vulnerability of the communities to these hazards. The findings of this study will aid in future planning and development of mitigation strategies associated with hydrological hazards.

Keywords: Climatic Variability and Changes; Consequence Level; Drought and Flood Risk Rating; Hydrological Hazards; Mitigation Strategies; Risk and Vulnerability.

\section{Introduction}

Hydrological hazards are hydrological events capable of inflicting damage to human and animal life and/or property (Mulugeta et al. 2007). Spatio-temporal variability in precipitation is one of the factors that increase the occurrence and risks of these hazards. The most common hydrological hazards in southern Africa are floods and droughts because of extreme weather patterns associated with a highly variable climate. Convective clusters associated with the Inter-Tropical Convergence Zone (ITCZ) are believed to produce very strong gusty winds and torrential rainfall, which result in floods in southern Africa (Moolchan 2010). El Niño-Southern Oscillation's influence also gives rise to floods and droughts, manifested in La Nina and El Nino, respectively. Droughts and floods have also become common because of increases in temperatures. In Limpopo province, temperatures have risen by $1^{\circ} \mathrm{C}$ over recent years (Gbetibuou 2009). Drought is the usual aftermath of southern Africa's climatic changes and is one of the most important natural disasters in southern Africa (Unganai 1994). Throughout the 20th century, droughts have occurred over South Africa with great regularity (Vogel 1995). The 1991-1992 period witnessed one of the worst recent droughts recorded in the country because of far-reaching impacts felt through all sectors of society (Glantz, Betsill \& Crandall 1997; Vogel, Laing \& Monnik 2000).

Merz, Elmer and Thieken (2009) defined risk as the combination of the probability of a particular event and the impact that the event would cause. Majority of the risk reduction research and practice in South Africa is orientated towards structural measures or technical/hydrological component of the non-structural early warning systems (Benjamin 2008). Studies that integrate assessment of hydrological hazards, their trends, associated risks and vulnerabilities in South Africa are lacking. Vhembe District Municipality (VDM) (2011) listed floods and droughts as major disasters that occur in the study area. Given the variability in rainfall combined with poor infrastructure in some parts of VDM, the level of vulnerability increases tremendously. Disaster management by VDM is limited to taking post-disaster measures and implementing few early warning systems (Musyoki, Thifhufhelwi \& Murungweni 2016). Thus, identification of hazards (including their trends, probabilities of occurrence and associated risks and vulnerabilities), as has been undertaken in this study, is important. This will support disaster risk management in the study area. Flood frequency analysis (FFA) is also a part of hazard identification and 
risk assessment. Thus, the findings of this study will aid in strategic mitigation of hydrological hazards, in the future.

Figure 1 shows a few examples of the impacts of hydrological hazards within the VDM, South Africa. Figure $1 \mathrm{a}$ and $\mathrm{b}$ shows two bridges that collapsed as a result of 1999-2000 and 2011-2012 floods, respectively. Figure $1 \mathrm{c}$ and d shows crop failures in Mhinga Village and reduced water levels at Vondo Dam, respectively, because of drought.

\section{Key focus}

The key focus of this study was to assess hydrological hazards in VDM and quantify the risks and vulnerabilities associated with them.

\section{Objectives}

The objectives of the study include determination of drought and flood frequencies, rainfall and streamflow trends' analyses, and assessment of risk and vulnerabilities of communities within VDM.

\section{The study area}

Luvuvhu River Catchment (LRC) within VDM (Figure 2) was selected as the study area. It is situated in the northernmost part of South Africa in Limpopo province on the windward side of the Soutpansberg Mountain range, which influences the rainfall pattern in that area and also the probabilities of the occurrence of hydrological hazards and associated risks. The LRC covers an area of approximately $5941 \mathrm{~km}^{2}$ (DWAF 2002). Figure 2 shows the location of the study area, which lies between latitude $22^{\circ} 6^{\prime} 0^{\prime \prime} \mathrm{S}$ and $23^{\circ} 25^{\prime} 0^{\prime \prime} \mathrm{S}$, and longitude $28^{\circ} 25^{\prime} 0^{\prime \prime} \mathrm{E}$ and $30^{\circ} 55^{\prime} 0^{\prime \prime} \mathrm{E}$.

The quantity as well as spatial-temporal distribution of precipitation within VDM is highly variable (Odiyo, Makungo \& Nkuna 2015). High rainfall is usually experienced
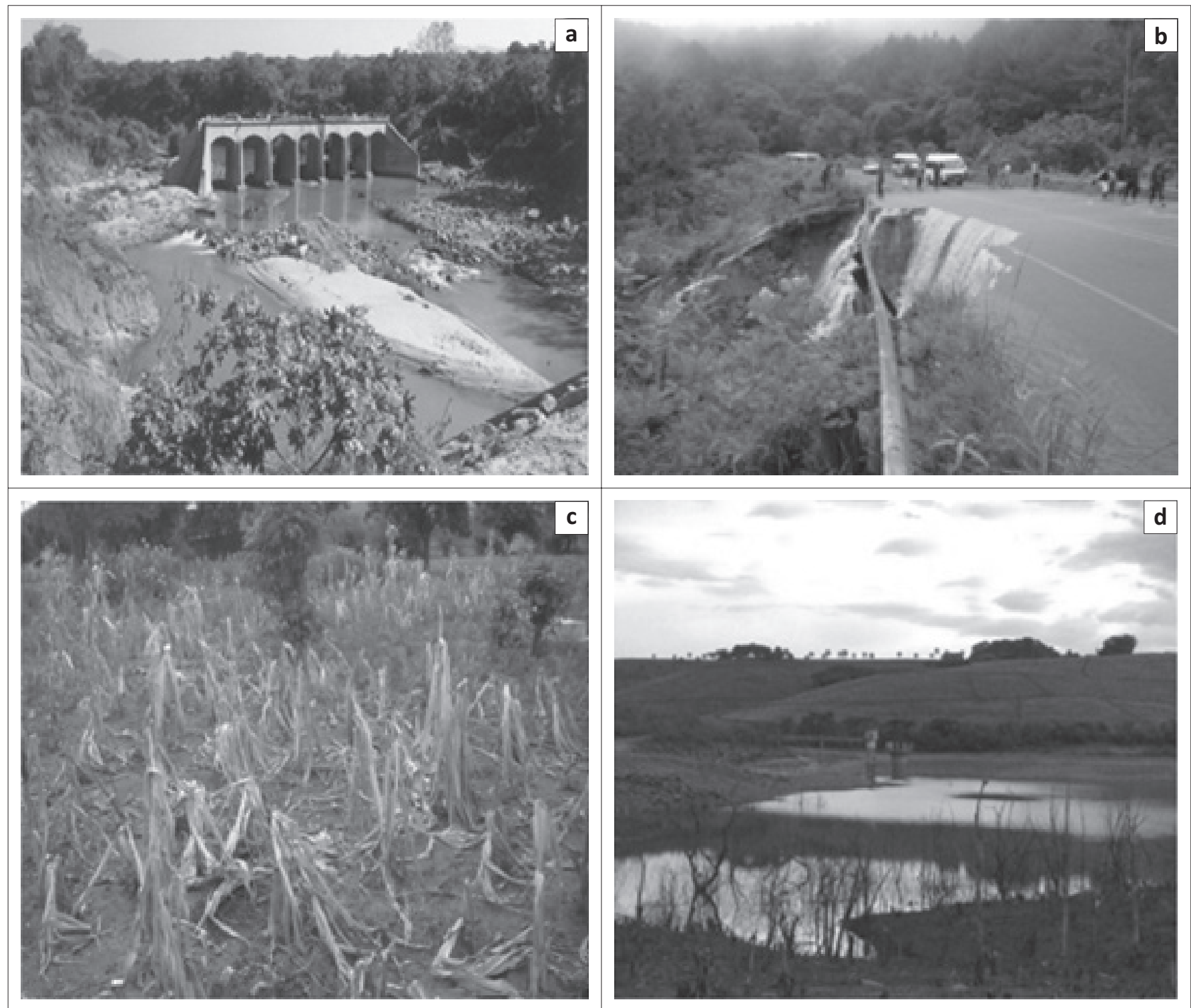

Source: (a) WRC (2001); (b) VDM (2011)

FIGURE 1: Examples of the impacts of hydrological hazards in Vhembe District Municipality: (a) Latonyanda Bridge collapse (1999-00 flood); (b) Thathe Vondo Bridge collapse 2011-12 flood); (c) Crope failure at Mhinge Village (2014-15 grought); (d) Reduced water levels in Vondo Dam (08/11/2016). 


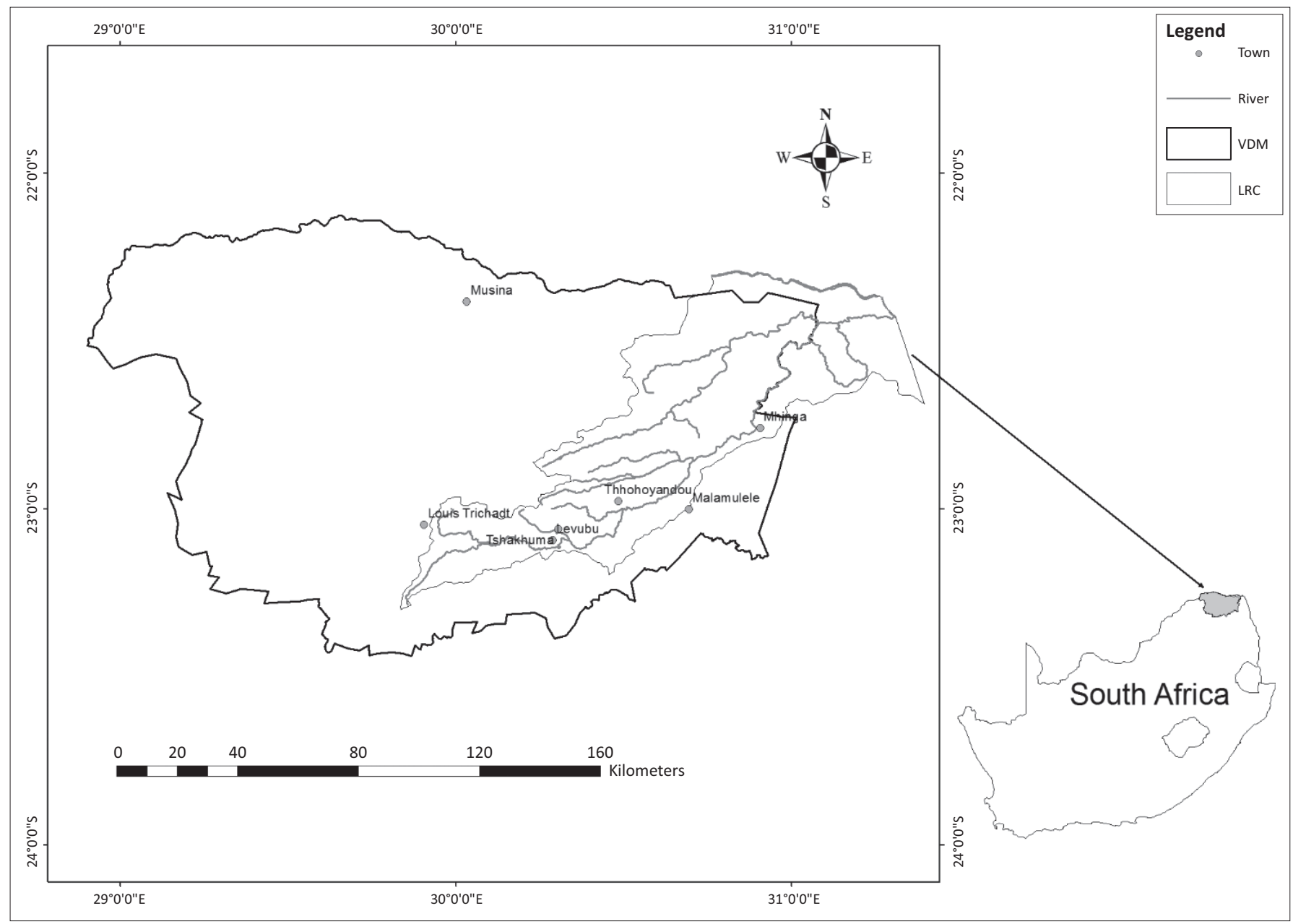

FIGURE 2: The study area.

in Tshakhuma and Levubu areas, while Mhinga Village receives very little rainfall. The LRC was selected because it is the economic hub of VDM with major commercial farms located in the Levubu Valley. There have also been a number of destructive floods and droughts with serious consequences on infrastructure and communities. Regular occurrences of hydrological hazards negatively impact agricultural production and rural communities' livelihoods. The LRC is generally characterised by limited high potential agricultural soil. Soils acquired in LRC showed sandy, clay and loamy textures.

\section{Methodology \\ Data sources and acquisition}

Daily rainfall data from 12 rainfall stations for 1959-1960 to 2007-2008 were obtained from South African Weather Service (SAWS) and Department of Water and Sanitation (DWS), while daily streamflow data for six streamflow gauging stations for 1959-1960 to 2013-2014 were obtained from DWS.

The study considered rainfall and streamflow stations in the upper and middle reaches of the catchment. Stations in the lower reaches of the catchment were not suitable for the study because they did not have adequate data to cover the minimum required period (30 years) considered in this study because of gaps and/or short records. This limited the number of stations used in the study. World Meteorological Organization (WMO) recommended 30 years as ideal for studying long-term climate change and trends' analysis. MacKellar, New and Jack (2014) used 50-years-long data to model rainfall and temperature trends in South Africa. Study periods adopted for this study were 33-49 and 39-55 years for rainfall and streamflow, respectively, because both rainfall and streamflow data from selected stations varied in the length of period of data availability. Figure 3 shows locations of rainfall and streamflow stations in LRC.

\section{Determination of flood frequency}

Flood peaks corresponding to return periods $\left(\mathrm{Tr}_{\mathrm{s}}\right)$ of 2, 5, 10, 50, 100 and 200 years were estimated using Log-Pearson Type III (LP3) distribution. Log-Pearson Type III is a member of the family of Pearson Type 3 distributions (Millington et al. 2011) defined by the mean, standard deviation and skew coefficient of the logarithms of stream discharge (Oberg \& Mades 1987). Log-Pearson Type III is used for estimating recurrence interval of flood events. Streamflow data were used to estimate $\operatorname{Tr}_{s^{\prime}}$ followed by extrapolating 100 and 200 years' flood events from the plot. The details of the 


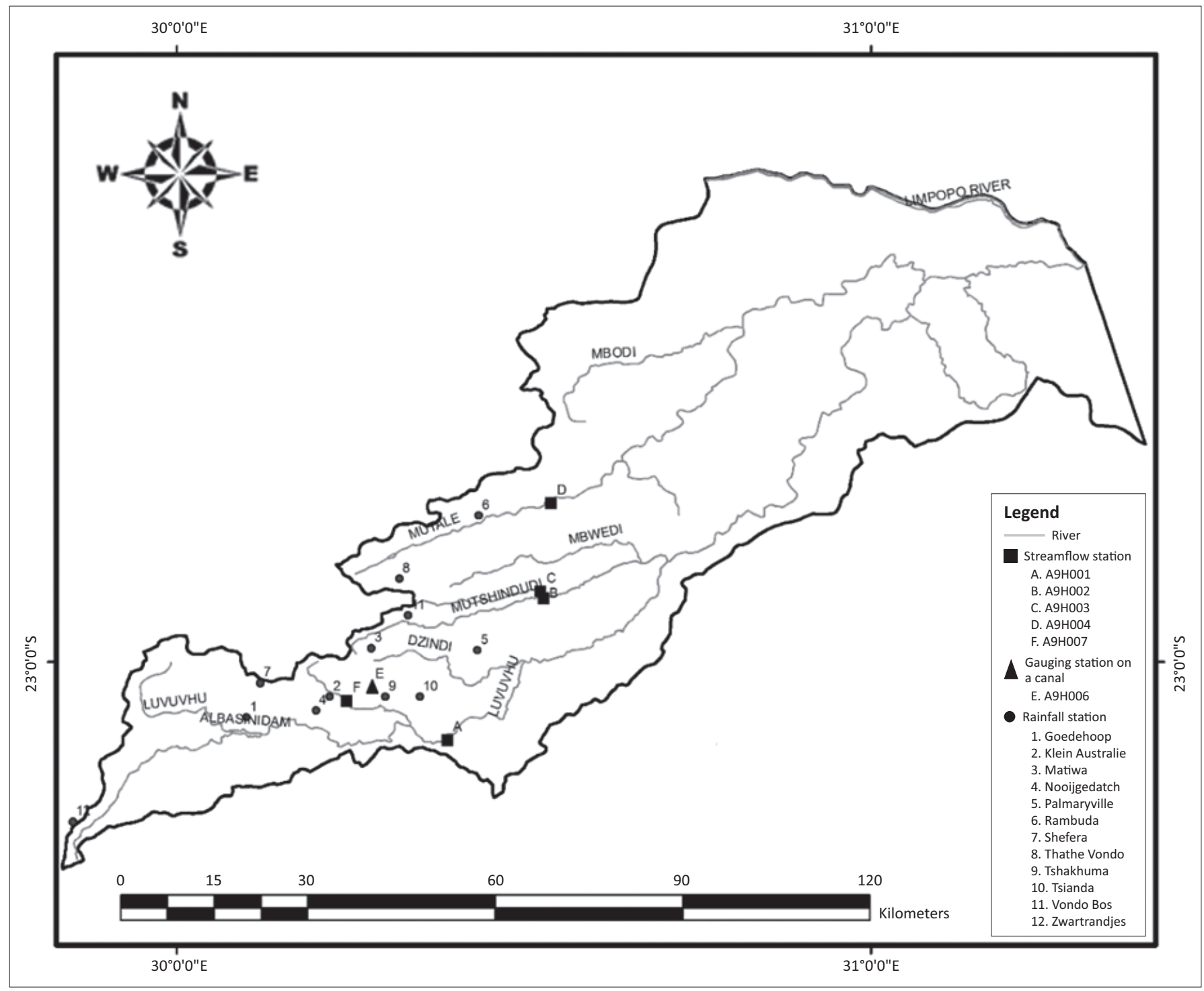

FIGURE 3: Locations of rainfall and streamflow stations.

six streamflow stations used in this study are given in Table 1. Owemoje and Owemooje (2011) suggested that in predicting maximum floods with $\operatorname{Tr}_{\mathrm{s}}$ of 25-year and 50-year periods, LP3 should be used with Weibull plotting position. Weibull plotting position refers to the probability value assigned to each streamflow event to be plotted; thus it uses the relationship between streamflow against corresponding probability of exceedance. Log-Pearson Type III has been widely used in South Africa to estimate $\operatorname{Tr}_{\mathrm{s}}$ of floods (Alexander 2001; Singo et al. 2012). Shorter $\operatorname{Tr}_{\mathrm{s}}$ were used to assess the effects of floods on rural communities, particularly on food production and daily livelihood.

To assess how floods affect built-up areas, the degree of protection was considered for floods with Tr of 100 or 200 years. Each computed flood magnitude was determined at 95\% confidence interval, which contained the true flood magnitude for a particular exceedance probability. Annual daily maximum (ADM) flood discharge series were extracted for each hydrological year (starting from October of one year to September of the following year). Estimated discharge values $X_{T}$ for a given period were evaluated using the logarithm of the design flood given as:

$X_{T}=\log Q_{T}=X_{a v}+K \sigma_{X}$

[Eqn 1]

where $Q_{T}$ is the discharge for estimated $\operatorname{Tr}, K$ is the probability factor based on $n$-years recurrence interval, $X_{a v}$ is the mean of the logarithms of annual peak flows $\left(X_{T}\right)$ and $\sigma_{x}$ is the standard deviation regarding the mean of the logarithm of ADM. Skewness coefficient G (Eqn. 2) was computed as an important hydrological characteristic that gives a measure of sampling distribution shape.

$G=\frac{n \sum(X-\bar{X})^{3}}{(n-1)(n-2) S^{3}}$

[Eqn 2]

$X$ is the logarithm of annual peak flow, $\bar{X}$ is sample mean, $n$ is length of data set and $S$ is sample standard deviation. The probability of occurrence of flood peaks corresponding to $\operatorname{Tr}_{\mathrm{s}}$ of 2, 5, 10, 50, 100 and 200 years for each station was 
TABLE 1: Selected rainfall and streamflow stations and their geographic location reflecting years of data coverage.

\begin{tabular}{|c|c|c|c|c|c|}
\hline Station number & Station type & Station name & Station location & Data span & Data length \\
\hline А9H001 & Streamflow & Luvuvhu River @ Weltevreden & Lat - 23.11242, Lon - 30.38949 & 1960-2005 & 46 \\
\hline А9H002 & Streamflow & Mutshindudi River @ Chibase & Lat - 22.90799, Lon - 30.52810 & 1960-1999 & 40 \\
\hline А9H003 & Streamflow & Tshinane River @ Chibase & Lat - 22.89814 , Lon - 30.52378 & 1959-2013 & 55 \\
\hline А9H004 & Streamflow & Mutale River @ Tengwe & Lat - 22.77105, Lon - 30.53894 & 1960-2004 & 45 \\
\hline А9H006 & Streamflow & Livhungwa River @ Barotta & Lat - 23.03572, Lon - 30.27748 & $1963-2014$ & 52 \\
\hline А9H007 & Streamflow & Latonanda River @ Levubu Settlement & Lat - 23.05575, Lon - 30.24476 & 1961-1999 & 39 \\
\hline $0723363 x$ & Rainfall & Klein Australie & Lat - 23.0500, Lon - 30.22 & $1959-2007$ & 49 \\
\hline 07665099 & Rainfall & Matiwa & Lat -22.9800 , Lon - 30.28 & 1959-2008 & 50 \\
\hline 07236030 & Rainfall & Tsianda & Lat - 23.0550, Lon - 30.350 & 1959-2008 & 50 \\
\hline $0723334 X$ & Rainfall & Nooitgedatch & Lat -23.0700 , Lon - 30.20 & 1959-2008 & 50 \\
\hline 0723182 & Rainfall & Shefera & Lat - 23.0300, Lon - 30.1200 & 1959-2008 & 50 \\
\hline 07668274 & Rainfall & Rambuda & Lat - 22.7889, Lon - 30.4347 & $1959-2008$ & 50 \\
\hline 07665969 & Rainfall & Vondo Bos & Lat - 23.9330, Lon - 30.333 & $1963-2008$ & 46 \\
\hline $0723513 x$ & Rainfall & Tshakhuma & Lat - 23.0500 , Lon - 30.300 & 1959-2008 & 50 \\
\hline 07226143 & Rainfall & Zwartranjies & Lat - 23.2300, Lon - 29.85 & $1959-2008$ & 50 \\
\hline 07665631 & Rainfall & Thathe Vondo & Lat -22.8800 , Lon - 30.32 & $1963-2000$ & 38 \\
\hline
\end{tabular}

computed using Eqn 3. The regression line from the probability plot was extended to cover $\operatorname{Tr}$ of 50, 100 and 200 years.

$P=\frac{1}{T_{r}}$

$P$ is the probability of occurrence.

\section{Standardised Precipitation Index}

Standardised Precipitation Index (SPI) (McKee, Doesken \& Kleist 1993) uses a standardisation procedure that transforms rainfall data to derive standardised anomalies. Rainfall data for 12 stations covering $34-50$ years (Table 1 ) were used in the analysis. Standardisation procedure aids in discerning normal and typical values and is symmetrical for the occurrence of wet and dry events (Sutton and Kempi 1993). The data were standardised using the following equation, as defined by Goddard and Melville (1996):

$Z=\frac{x_{i}-\bar{x}}{s}$

[Eqn 4]

where $\bar{x}$ is the sample mean, $Z$ is the normalised standardised departure, $x_{i}$ is the six-months mean value and $s$ is the sample standard deviation.

Six months SPI (SPI-6) was selected for drought frequency analysis. Six months SPI at the end of March gives a very good indication of the amount of precipitation that has fallen during the wet period (WMO 2012). The wet period in the study area is from October to March, and thus SPI-6 has the ability to show deficiency in rainfall, which is an indicator of drought. Standardised Precipitation Index is particularly suited to compare drought conditions among different time periods and regions with different climates (Cacciamani et al. 2007). Standardised Precipitation Index categories (Table 2) defined by WMO (2012) were used to classify drought years as they included $\operatorname{Tr}_{\mathrm{s}}$ for drought events within each category.
TABLE 2: Probabilities of recurrence for different SPI values and categories.

\begin{tabular}{lll}
\hline SPI & Category & Tr \\
\hline 0 to -0.99 & Mild dryness & 3 \\
-1.00 to -1.49 & Moderate dryness & 10 \\
-1.5 to -1.99 & Severe dryness & 20 \\
$<-2.0$ & Extreme dryness & 50 \\
\hline
\end{tabular}

Source: Adapted from WMO (2012)

SPI, Standardised Precipitation Index.

\section{Rainfall and streamflow trend detection}

In this study, Mann-Kendall (non-parametric) trend test (Kendall 1975; Mann 1945) was used to detect trends and their significance for ADM rainfall and streamflow. MannKendall trend test (Kendall \& Gibson 1990; Mann 1945) has been widely applied and has the advantage that the power and significance are not affected by actual distribution unlike the parametric distributions. This method has been applied widely in hydro-meteorological trend analysis studies (Burn \& Hesch 2007; Hamed 2008; Hirsh, Slack \& Smith 1982; Longobardi \& Villani 2009; Nenwiini \& Kabanda 2013; Nury, Koch \& Alam 2014; Odiyo et al. 2015).

Paired two-tailed $t$-tests were used to verify significant or non-significant differences between ADM rainfall and streamflow trends. Trends were analysed using a 95\% confidence level (i.e. a significance level [alpha] of 0.05). The null hypothesis $\left(\mathrm{H}_{\mathrm{o}}\right)$, which suggests there is no trend, was tested against the alternative hypothesis $\left(\mathrm{H}_{1}\right)$, which suggests there is a trend. Mann-Kendall trend test analyses the sign of the difference between later and earlier measured data values (Nury et al. 2014). Each later value is compared to all values measured earlier, resulting in a total number of observations. Initial value of Mann-Kendall statistic, $S$, is zero, and this indicates that there is no trend in data series (Hirsh et al. 1982). If $S$ is a large positive number, later values tend to be larger than earlier values and an upward trend is indicated. When $S$ is a large negative number, later values tend to be smaller than earlier values and a downward trend is indicated. 


\section{Risks and vulnerabilities}

In this study, risk was adopted from Wilhite, Sivakumar and Pulwarty (2014) using both exposure of a location to drought or flood hazard and vulnerability of that location to periods of drought-induced water shortages or water surplus as a result of floods. The likelihood and consequence categories for the risk matrix were determined for each flood event based on a methodology by Ayyub (2003). The corresponding consequence level (CL) of each flood event was multiplied by its likelihood (LL) in order to find out the risk rating (RR) for each impact using Eqn. 5:

$R R=C L \times L L$

[Eqn 5]

CL and LL were obtained based on Tr and probability of occurrence of a flood event. In this case, CL and LL categories were assigned corresponding to each $\mathrm{Tr}$ and probability. These were later described in terms of their frequency of occurrence and their likely impact. For drought risk analysis, LL was determined from likelihood table based on computed probabilities of occurrence for each drought category within each station following UV and NDGDM (2013). Standardised consequence table from UV and NDGDM (2013) was used to determine CL. Qualitative risk matrix combined LL and CL to determine the risk level. In this study, vulnerability was based on how the impact affects rural communities, particularly on food production and daily livelihoods. Risk rating shows the vulnerability of rural communities to hydrological hazards.

\section{Results and discussions Flood frequency analysis}

Figure 4 depicts $\mathrm{Tr}$ plot of ADM streamflow for stations A9H001, A9H002, A9H003, A9H004, A9H006 and A9H007 in the study area, with each station's coefficient of determination $\left(R^{2}\right) . R^{2}$ describes the degree of collinearity between two variables and ranges from zero to one, with higher values indicating less error variance, and typically, values greater than 0.5 are considered acceptable (Santhi et al. 2001; Van Liew, Arnold \& Garbrecht 2003). There is a linear relationship between ADM streamflow and Tr with $R^{2}$ of stations A9H001 and A9H003 being 0.6464 and 0.6226 , respectively. The latter stations showed the lowest linear relationships of the six stations. Stations A9H002, A9H004, A9H006 and A9H007 have $R^{2}$ of above 0.9. Although stations A9H001 and A9H003 reported lower $R^{2}$, it is still greater than 0.5 , which is indicative of a linear relationship. These results indicate that linear relationship between Tr and ADM streamflow from stations A9H001 and A9H003 is less significant than that of stations A9H002, A9H004, A9H006 and A9H007.

Flood peaks corresponding to $\operatorname{Tr}$ of 2, 5, 10, 25, 50, 100 and 200 years were estimated for flood prevention and protection from risks in the catchment at different probabilities of exceedance. Log-Pearson Type III estimated discharges are shown in Table 3.
The lowest Tr corresponded to high probability of occurrence (see Eqn. 3) and low estimated streamflow for each station. A two-year $\operatorname{Tr}$ with a $100 \%$ probability of occurrence corresponded to 14.01, 6.06, 2.97, 9.05, 3.00 and $67.77 \mathrm{~m}^{3} / \mathrm{s}$ for stations A9H001, A9H003, A9H006, A9H002, A9H007 and $\mathrm{A} 9 \mathrm{H} 004$, respectively. Because of variation in data length, streamflows corresponding to $\mathrm{Tr}$ of 50, 100 and 200 years were extrapolated for stations A9H001, A9H002, A9H004 and A9H007, while for station A9H003 and A9H006 extrapolation was performed for only streamflow corresponding to $\mathrm{Tr}$ of 100 and 200 years. Extrapolated streamflow showed that flood magnitude increases with a lower probability of occurrence and a high Tr. -Two hundred years $\operatorname{Tr}$ at $22.1 \%$ probability of occurrence corresponded to 230, 110, 40, 113, 16 and $520 \mathrm{~m}^{3} / \mathrm{s}$ for stations A9H001, A9H003, A9H006, A9H002, A9H007 and A9H004, respectively. Results of this study, therefore, indicate that a low magnitude flood with a low $\mathrm{Tr}$ has the highest probability of occurrence, while a high magnitude flood with a high Tr has the lowest probability of occurrence and is likely to result in the largest damage in the study area. Karlsson and Haimes (1988) indicated that a low probability expectation is a measure of the average largest damage, given the events of an extreme nature. Therefore, the results of this study follow the concept of 'high probability/low damage' and 'low probability/high damage' as explained in Merz et al. (2009).

\section{Drought frequency analysis}

Figure 5 displays fluctuations of wet and dry years, which show the variable nature of rainfall in the study area. Mild dryness condition dominated the dry years in all stations with probabilities of occurrence ranging from $22.4 \%$ to $59.2 \%$ (Table 4). Mild dryness condition has a Tr of three years, showing that the prevalence of occurrence of mild dryness is high in the study area. Communities within the vicinity of these stations are therefore regularly affected by droughts. Moderate dryness condition had a probability of occurrence from $4.1 \%$ to $18.4 \%$ with a $\operatorname{Tr}$ of 10 years. The latter, just like the mild dryness category, has a high prevalence in the study area. Severe dryness had a probability of occurrence of $2 \%$ in most of the stations, while extreme dryness condition had a probability of occurrence of $2 \%$ in Rambuda and Thathe. Six stations (Palmaryville, Rambuda, Shefera, Tsianda, Vondo Bos and Zwartrandjes) each had a probability of occurrence of dry years exceeding 50\%, with Palmaryville and Rambuda having the highest percentages of probability of occurrence of dry years of $63.2 \%$ and $65.3 \%$, respectively (Table 4 ). This shows the prevalence of drought conditions in the areas within the vicinity of these stations. Tsianda, Palmaryville and Rambuda also had more than 50\% probabilities of occurrence of mild dryness.

Seven stations (Palmaryville, Matiwa, Tsianda, Rambuda, Shefera, Thathe and Zwartrandjes) displayed the 1997-1998 (Figure 5) drought that was recorded in the north-eastern interior region of South Africa during El Nino in a study by 

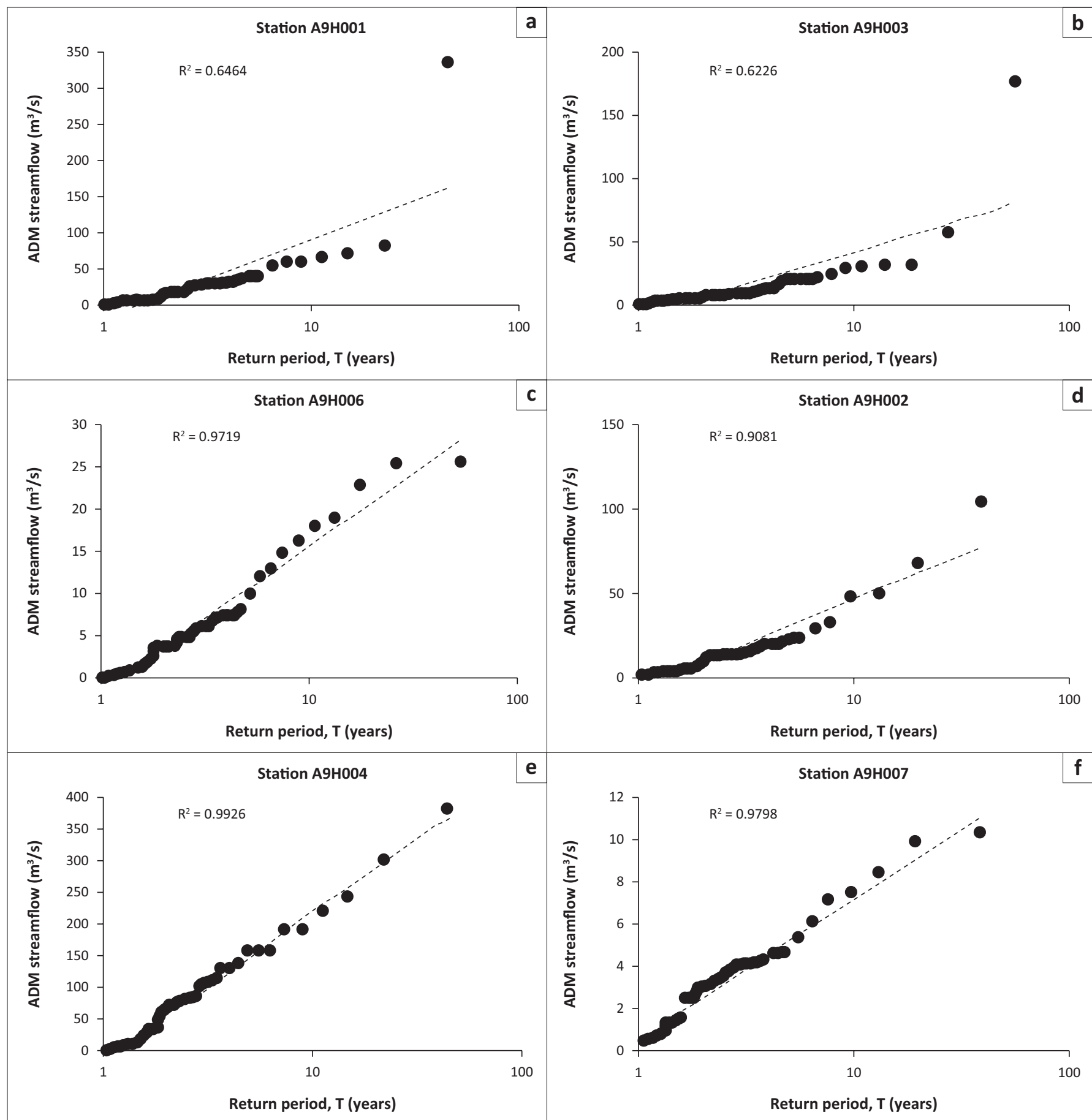

FIGURE 4: Annual daily maximum streamflow versus $\operatorname{Tr}$ plot for selected stations in the study area.

TABLE 3: Tr and probability of annual daily maximum streamflow.

\begin{tabular}{|c|c|c|c|c|c|c|c|c|c|c|c|c|}
\hline \multirow[t]{2}{*}{$\mathrm{Tr}$} & \multicolumn{2}{|c|}{ А9H001 } & \multicolumn{2}{|c|}{ А9H003 } & \multicolumn{2}{|c|}{ А9H006 } & \multicolumn{2}{|c|}{ А9H002 } & \multicolumn{2}{|c|}{ А9H007 } & \multicolumn{2}{|c|}{ А9H004 } \\
\hline & $P(\%)$ & $Q\left(m^{3} / s\right)$ & $P(\%)$ & $\mathrm{Q}\left(\mathrm{m}^{3} / \mathrm{s}\right)$ & $P(\%)$ & $\mathrm{Q}\left(\mathrm{m}^{3} / \mathrm{s}\right)$ & $P(\%)$ & $\mathrm{Q}(\mathrm{m} 3 / \mathrm{s})$ & $P(\%)$ & $\mathrm{Q}\left(\mathrm{m}^{3} / \mathrm{s}\right)$ & $P(\%)$ & $\mathrm{Q}\left(\mathrm{m}^{3} / \mathrm{s}\right)$ \\
\hline 2 & 1 & 14.01 & 1 & 6.06 & 1 & 2.97 & 1 & 9.05 & 1 & 3 & 1 & 67.77 \\
\hline 5 & 0.999 & 39.45 & 0.999 & 20.07 & 0.999 & 9.1 & 0.999 & 21.14 & 0.999 & 4.69 & 0.999 & 155.14 \\
\hline 10 & 0.994 & 61.99 & 0.994 & 28.84 & 0.994 & 18.68 & 0.994 & 48.18 & 0.994 & 7.46 & 0.994 & 206.59 \\
\hline 25 & 0.923 & 101.53 & 0.923 & 50.3 & 0.923 & 24.85 & 0.923 & 76.55 & 0.923 & 9.99 & 0.923 & 310.42 \\
\hline 50 & 0.635 & 169.00 & 0.635 & 80.00 & 0.635 & 28.00 & 0.635 & 82.00 & 0.635 & 11.80 & 0.635 & 340.00 \\
\hline 100 & 0.394 & 197.00 & 0.394 & 100.00 & 0.394 & 32.00 & 0.394 & 98.00 & 0.394 & 13.80 & 0.394 & 450.00 \\
\hline 200 & 0.221 & 230.00 & 0.221 & 110.00 & 0.221 & 40.00 & 0.221 & 113.00 & 0.221 & 16.00 & 0.221 & 520.00 \\
\hline
\end{tabular}




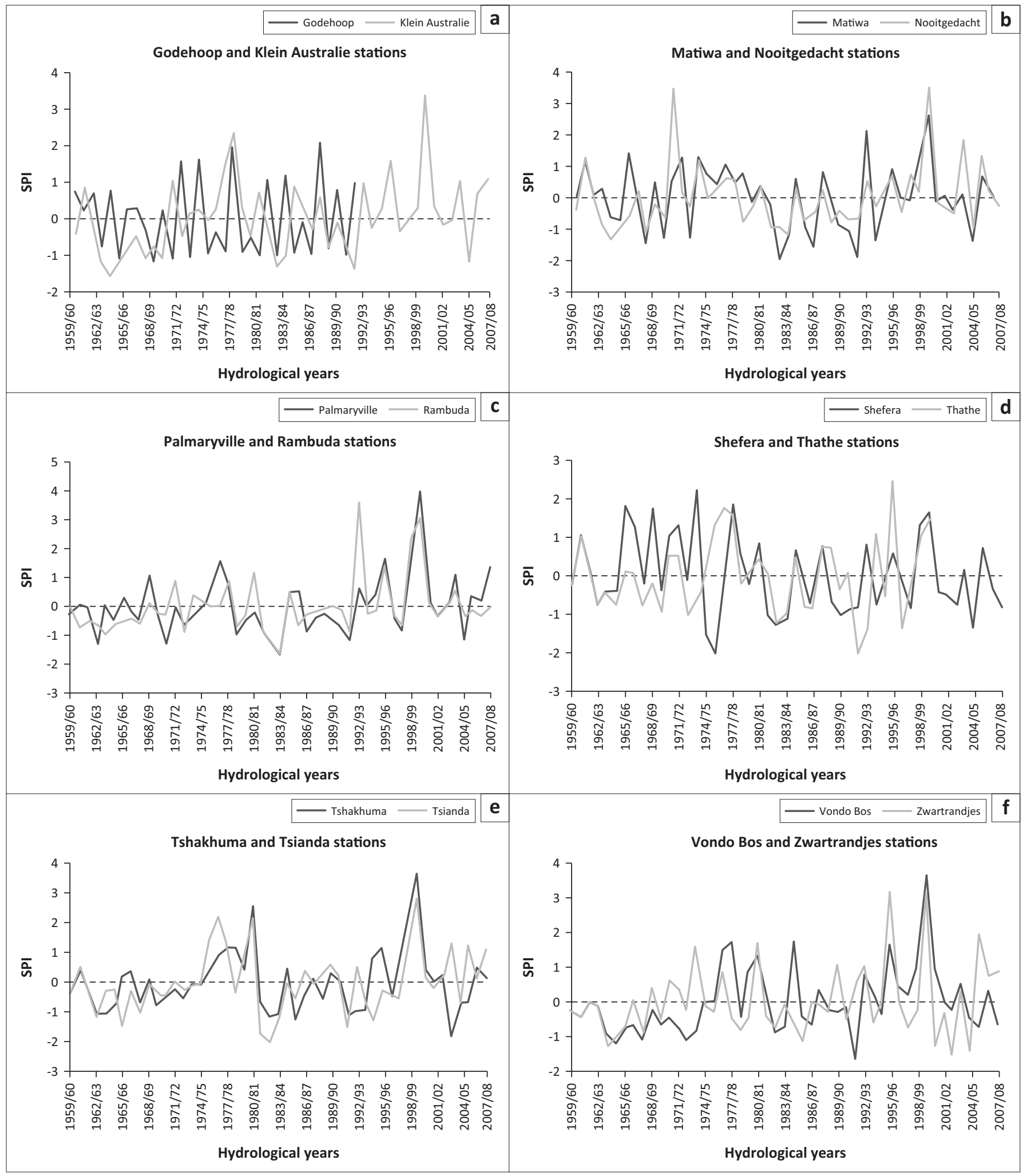

FIGURE 5: Standardised Precipitation Index for stations in the study area.

Rouault and Richard (2003). Lindesay and Vogel (1990) and Edossa, Woyessa and Welderufael (2014) have shown that El Nino is usually associated with drought condition in South Africa. The years 1982-1983 and 1991-1992 in moderate and extreme dryness categories were classified as the two strongest droughts within the last two decades, by
Rouault and Richard (2003). These droughts are clearly shown in the selected stations in this study (Figure 5). Other notable drought years as depicted by the SPI plot of the stations in the LRC include but are not limited to 1962-1963, 1964-1965, 1972-1973, 1986-1987, 1993-1994, 2001-2002 and 2004-2005. 


\section{Rainfall and streamflow trend analysis}

Mann-Kendall trends test results for rainfall and streamflow are presented in Table 5 and Table 6, respectively. The stations with significant positive or negative trends are reported at a confidence interval of 95\%. Longobardi and Villani (2009) used non-parametric trend test at confidence levels of $99 \%, 95 \%$ and $90 \%$ while assessing trends of annual and seasonal rainfall time series in the Mediterranean area. The latter study successfully detected trends at 99\%,95\% and 90\% confidence levels and reported predominant negative trends at both annual and seasonal scales with exception of summer months when the trend appeared to be positive. Karmeshu (2012) tested the null hypothesis at $95 \%$ confidence level for temperature and precipitation data in nine states in the USA. Results of Karmeshu (2012) found significantly increasing trends for both precipitation and temperature, for seven of the eight states.

About $25 \%$ of rainfall stations depicted downward trends, while $75 \%$ showed positive upward trends for the rainfall time series. Of the nine stations that exhibited an upward trend, four stations showed that the trend was statistically significant, while Tsianda, Entabeni-Bos, Nooitgedatch, Thathe and Zwartrandjes stations had insignificant positive trends. All stations that exhibited downward trends reported insignificant trends. About $16.7 \%$ of streamflow stations depicted downward trends, while $83.3 \%$ depicted upward trends. Upward trends for streamflow were statistically significant for station $\mathrm{A} 9 \mathrm{H} 003$ and insignificant for stations A9H001 and A9H006. Stations A9H002, A9H004 and A9H007 all exhibited significantly downward trends.

The results on trends analyses obtained in this study are comparable with those obtained by Odiyo et al. (2015) with some stations having the same trend characteristic. For example, Odiyo et al. (2015) found that Zwartrandjes rainfall station had an insignificant upward trend, while the streamflow station A9H006 also reported the same results. The latter comparability is not the case for the rest of the stations, this may be because Odiyo et al. (2015) used annual total time series, while this study used ADM time series for both rainfall and streamflow.

\section{Risk and vulnerabilities}

Table 7 shows quantified flood risk in the study area, including likelihood and consequence of the flood event. The likelihood of flood occurrence ranged from the probability of 0.22 to 1.00 . Because of the latter, the identified risks associated with floods had probabilities of more than 0.22 . This means that flood risks of category A with LL of six were likely to occur.

TABLE 4: Tr and probabilities of occurrence within each SPI category.

\begin{tabular}{|c|c|c|c|c|c|c|c|c|c|c|c|c|c|}
\hline Category & $\operatorname{Tr}$ & GP & KA & MA & NT & $\mathrm{PE}$ & RA & SA & TT & TS & TA & VB & ZS \\
\hline Mild dryness & 3 & 28.6 & 28.6 & 22.4 & 22.4 & 51.0 & 59.2 & 42.9 & 24.5 & 36.7 & 51.0 & 44.9 & 36.7 \\
\hline Moderate dryness & 10 & 8.2 & 16.3 & 18.4 & 6.1 & 10.2 & 4.1 & 8.2 & 12.2 & 6.1 & 6.1 & 10.2 & 12.2 \\
\hline Severe dryness & 20 & - & 2.0 & 2.0 & 0.0 & 2.0 & 0.0 & 0.0 & 0.0 & 2.0 & 2.0 & 2.0 & 2.1 \\
\hline Extreme dryness & 50 & 0.0 & 0.0 & 0.0 & 0.0 & 0.0 & 2.0 & 0.0 & 2.0 & 0.0 & 0.0 & 0.0 & 0.0 \\
\hline Total & & 36.7 & 46.9 & 42.9 & 28.5 & 63.2 & 65.3 & 51.1 & 38.7 & 44.8 & 59.1 & 57.1 & 51.0 \\
\hline
\end{tabular}

GP, Godehoop; KA, Klein Australie; MA, Matiwa; NT, Nooitgedacht; PE, Palmaryville; RA, Rambuda; SA, Shefera; TT, Thathe; TS, Tshakhuma; TA, Tsianda; VB, Vondo Bos; ZS, Zwartrandjes; SPI, Standardised Precipitation Index.

TABLE 5: Mann-Kendall trends for rainfall stations.

\begin{tabular}{lccll}
\hline Station & $\boldsymbol{S}$ & $\boldsymbol{p}$ (two tailed test & Alpha & Test interpretation \\
\hline Shefera & -87.000 & 0.445 & 0.05 & Accept $\mathrm{H}_{\circ}$ \\
Tsianda & 47.000 & 0.692 & 0.05 & Accept $\mathrm{H}_{\circ}$ \\
Tshakhuma & -88.000 & 0.453 & 0.05 & Accept $\mathrm{H}_{\circ}$ \\
Palmaryville & 86.000 & 0.000 & 0.05 & Reject $\mathrm{H}_{\circ}$ \\
Entabeni-Bos & 85.000 & 0.469 & 0.05 & Accept $\mathrm{H}_{\circ}$ \\
Klein-Australie & 276.000 & 0.017 & 0.05 & Downward \\
Nooitgedacht & 89.000 & 0.448 & 0.05 & Reject $\mathrm{H}_{\circ}$ \\
Matiwa & -31.000 & 0.790 & Accept $\mathrm{H}_{\circ}$ \\
Rambuda & 288.000 & 0.011 & Accept $\mathrm{H}_{\circ}$ \\
Vondo Bos & 240.000 & 0.016 & Upward \\
Thathe & 98.000 & 0.05 & Reject $\mathrm{H}_{\circ}$ \\
Zwartrandjes & 62.000 & 0.05 & Reject $\mathrm{H}_{\circ}$ \\
\hline
\end{tabular}

TABLE 6: Mann-Kendall trends for selected streamflow stations.

\begin{tabular}{|c|c|c|c|c|c|c|}
\hline Station & $S$ & $p$ (two tailed test & Alpha & Test interpretation & Trend & Significant \\
\hline А9H001 & 30.00 & 0.778 & 0.05 & Accept $\mathrm{H}_{0}$ & Upward & No \\
\hline А9H003 & 386.00 & 0.004 & 0.05 & Reject $\mathrm{H}_{\mathrm{o}}$ & Upward & Yes \\
\hline А9H006 & 204.00 & 0.109 & 0.05 & Accept $\mathrm{H}_{0}$ & Upward & No \\
\hline А9H002 & -740.00 & $<0.0001$ & 0.05 & Reject $\mathrm{H}_{\mathrm{o}}$ & Downward & Yes \\
\hline А9H004 & -902.00 & $<0.0001$ & 0.05 & Reject $\mathrm{H}_{\mathrm{o}}$ & Downward & Yes \\
\hline А9H007 & -700.00 & $<0.0001$ & 0.05 & Reject $\mathrm{H}_{0}$ & Downward & Yes \\
\hline
\end{tabular}


The RR for floods was assessed for Damage to Houses and Household Products (DHHP), Inundation of Roads Networks and Their Damage and Destruction (IRDD), Damage to Crops and Losses of Livestock (DCLL), Erosion of Agricultural Lands (EAL), problems in relocation of people, Spread of Diseases (SD) and Effects on Health (Hossain 2014). The latter flood impacts categories were selected based on the fact that historical floods in the study area tended to damage houses (International Federation's Disaster Relief Emergency Fund [IFDREF] 2011), damage road networks (Figure 1a and b), affect agricultural productivity and spread of water borne diseases. The results from Table 7 showed that high $\mathrm{T}_{r}$ correlated with low probability and high RR.

The results showed catastrophic consequence levels for station A9H001 at 50, 100 and 200 years $\mathrm{T}_{\mathrm{r}}$. Stations A9H003 and $\mathrm{A} 9 \mathrm{H} 007$ depicted catastrophic consequence levels for both 100 and 200 years Tr. A9H002, A9H004 and A9H006 had catastrophic consequence levels for 200 years Tr. Two hundred years Tr in all stations showed a highest consequence level. Risk associated with 200 years Tr has the ability to cause major damage to houses and household products, and cause destruction to the environment. Tr of 10 years had a serious consequence level for station A9H001 and significant consequences for A9H002 and A9H004 stations. Significant consequence levels were found in stations A9H002 (10 and 25 Tr), A9H003 (25 and 50 Tr), A9H004 (10, 25 and 50 Tr), A9H006 (100 Tr) and A9H007 (50 Tr). The results therefore show that serious, significant and catastrophic DHHP, IRDD, DCLL, EAL and SD were expected to occur within the localities of these stations for floods with the above-mentioned Tr. The results of this study are comparable with that of Hossain (2014), which showed that a higher value of RR corresponds to catastrophic impacts on DHHP, IRDD, DCLL, EAL and SD.
Station A9H001 had a high RR corresponding to 50, 100 and 200 years Tr, followed by stations A9H003 and A9H007 which had a high RR for 100 and 200 years Tr. A9H002, A9H004 and A9H006 only had a high RR for 200 years Tr. The latter therefore indicates that communities in the sub-catchment A9H001 would be at risk if a 50-year flood were to occur. The overall average RR for the study area was estimated as 19 . This corresponds to a CL of three and has the potential to result in significant consequences.

Table 8 shows LL, CLs and impacts of droughts with different probabilities of occurrence in the study area. The study area experiences mild dryness frequently when compared to the other three drought categories. Five rainfall stations (GP, KA, MA, NT and TV) in the mild dryness category had likely LLs (Table 3 and Table 7) that are associated with minor consequences. The rest of the stations (seven) in the mild dryness category (TS, ZS, SA, VB, PE, RA and TA) fell within almost likely likelihood with moderate consequences. Most stations dominated the moderate dryness category with major CL. This shows that minor and moderate, and major impacts associated with mild and moderate dryness, respectively, are frequent in the study area. Thus, communities are at risk and vulnerable to these hazards. Limpopo Economic Development, Environment and Tourism (LEDET) (2016) also reported that rural livelihoods in Thulamela Municipality within VDM are highly vulnerable to climate change-related impacts including drought.

The actual impacts of drought hazards are shown in Table 8 and are related to reduced supply or delivery services, loss of employment (in the agricultural sector), loss of ecosystems functions and public reactions. Table 8 also shows that the lower the probability of occurrence, the more severe the

TABLE 7: Flood risk in the study area.

\begin{tabular}{|c|c|c|c|c|c|c|c|c|c|c|c|c|c|c|c|c|c|c|c|}
\hline \multirow{2}{*}{$\begin{array}{l}\text { Station } \\
\text { number }\end{array}$} & \multirow[t]{2}{*}{$\mathrm{Tr}$} & \multirow[t]{2}{*}{$\mathbf{P}$} & \multicolumn{3}{|c|}{ Likelihood } & \multicolumn{3}{|c|}{ Consequence } & \multirow[t]{2}{*}{$\mathbf{R R}$} & \multirow{2}{*}{$\begin{array}{l}\text { Station } \\
\text { number }\end{array}$} & \multirow[t]{2}{*}{$\mathrm{Tr}$} & \multirow[t]{2}{*}{$\mathbf{P}$} & \multicolumn{3}{|c|}{ Likelihood } & \multicolumn{3}{|c|}{ Consequence } & \multirow[t]{2}{*}{$\mathbf{R R}$} \\
\hline & & & $\mathrm{C}$ & D & $\bar{L}$ & C & $\mathbf{L}$ & D & & & & & C & D & $\mathbf{L}$ & C & $\mathbf{L}$ & D & \\
\hline \multirow[t]{6}{*}{ A9H001 } & 2 & 1 & A & Likely & 6 & A & 1 & None & 6 & А9H0O2 & 2 & 1 & A & Likely & 6 & A & 1 & None & 6 \\
\hline & 5 & 0.999 & A & Likely & 6 & B & 2 & Minor & 12 & & 5 & 0.999 & A & Likely & 6 & A & 1 & None & 6 \\
\hline & 10 & 0.994 & A & Likely & 6 & D & 4 & Serious & 24 & & 10 & 0.994 & $A$ & Likely & 6 & $\mathrm{C}$ & 3 & Significant & 18 \\
\hline & 25 & 0.923 & $A$ & Likely & 6 & $\mathrm{E}$ & 5 & Major & 30 & & 25 & 0.923 & $A$ & Likely & 6 & $\mathrm{C}$ & 3 & Significant & 18 \\
\hline & 50 & 0.635 & A & Likely & 6 & $\mathrm{~F}$ & 6 & Catastrophic & 36 & & 50 & 0.635 & A & Likely & 6 & $E$ & 5 & Major & 30 \\
\hline & 200 & 0.221 & A & Likely & 6 & $\mathrm{~F}$ & 6 & Catastrophic & 36 & & 200 & 0.221 & A & Likely & 6 & $\mathrm{~F}$ & 6 & Catastrophic & 36 \\
\hline \multirow[t]{6}{*}{ А9H003 } & 2 & 1 & $A$ & Likely & 6 & A & 1 & None & 6 & А9H007 & 2 & 1 & A & Likely & 6 & A & 1 & None & 6 \\
\hline & 5 & 0.999 & A & Likely & 6 & A & 1 & None & 6 & & 5 & 0.999 & A & Likely & 6 & $A$ & 1 & None & 6 \\
\hline & 10 & 0.994 & A & Likely & 6 & B & 2 & Minor & 12 & & 10 & 0.994 & A & Likely & 6 & $A$ & 1 & None & 6 \\
\hline & 25 & 0.923 & A & Likely & 6 & C & 3 & Significant & 18 & & 25 & 0.923 & A & Likely & 6 & B & 2 & Minor & 12 \\
\hline & 50 & 0.635 & $A$ & Likely & 6 & C & 3 & Significant & 18 & & 50 & 0.635 & A & Likely & 6 & $\mathrm{C}$ & 3 & Significant & 18 \\
\hline & 100 & 0.394 & A & Likely & 6 & $\mathrm{~F}$ & 6 & Catastrophic & 36 & & 100 & 0.394 & A & Likely & 6 & $\mathrm{~F}$ & 6 & Catastrophic & 36 \\
\hline \multirow[t]{7}{*}{ А9H006 } & 2 & 1 & A & Likely & 6 & A & 1 & None & 6 & А9H004 & 2 & 1 & A & Likely & 6 & B & 2 & Minor & 12 \\
\hline & 5 & 0.999 & A & Likely & 6 & A & 1 & None & 6 & & 5 & 0.999 & A & Likely & 6 & B & 2 & Minor & 12 \\
\hline & 10 & 0.994 & A & Likely & 6 & A & 1 & None & 6 & & 10 & 0.994 & A & Likely & 6 & C & 3 & Significant & 18 \\
\hline & 25 & 0.923 & A & Likely & 6 & B & 2 & Minor & 12 & & 25 & 0.923 & A & Likely & 6 & C & 3 & Significant & 18 \\
\hline & 50 & 0.635 & A & Likely & 6 & B & 2 & Minor & 12 & & 50 & 0.635 & A & Likely & 6 & C & 3 & Significant & 18 \\
\hline & 100 & 0.394 & $A$ & Likely & 6 & C & 3 & Significant & 18 & & 100 & 0.394 & A & Likely & 6 & $E$ & 5 & Major & 30 \\
\hline & 200 & 0.221 & A & Likely & 6 & $\mathrm{~F}$ & 6 & Catastrophic & 36 & & 200 & 0.221 & A & Likely & 6 & $\mathrm{~F}$ & 6 & Catastrophic & 36 \\
\hline
\end{tabular}

C, category; D, description; L, level; $R R$, risk rating. 
TABLE 8: Drought probabilities, likelihood, consequence levels and impacts in the study area.

\begin{tabular}{|c|c|c|c|c|c|c|}
\hline Drought category & Probability of occurrence & Stations & Likelihood & Risk level & Consequence level & Impacts $^{\mathrm{a}}$ \\
\hline \multirow[t]{2}{*}{ Mild } & $20 \%-30 \%$ & GP, KA, MA, NT, TT, & Likely & Medium & Minor & $\begin{array}{l}\text { Isolated and temporary cases of reduced } \\
\text { supply services, loss of employment (in the } \\
\text { agricultural sector) and expressions of public } \\
\text { concern }\end{array}$ \\
\hline & $30 \%-60 \%$ & TS, ZS, SA, VB, PE, RA, TA & Almost likely & Medium & Moderate & $\begin{array}{l}\text { Isolated but significant impairment of loss of } \\
\text { ecosystems functions, ongoing reduced } \\
\text { services to community, wide spread public } \\
\text { protests, and mid -term failure of service } \\
\text { delivery. }\end{array}$ \\
\hline Moderate & $0 \%-20 \%$ & $\begin{array}{l}\text { GP, NT, RA, SA, TS, TA, KA, } \\
\text { MA, PE, TT, VB, ZS, }\end{array}$ & Likely & High & Major & $\begin{array}{l}\text { Multiple loss of lives, severe impairment or } \\
\text { loss of ecosystem functions, progressive } \\
\text { environmental damage, multiple business } \\
\text { failures and loss of employment, loss of public } \\
\text { confidence in governance, reduced quality of } \\
\text { life in community, mid to long term failure of } \\
\text { service delivery }\end{array}$ \\
\hline Severe & $0 \%-5 \%$ & KA, MA, PE, TS, TA, VB, ZS & Unlikely & High & Catastrophic & \multirow{2}{*}{$\begin{array}{l}\text { Widespread loss of lives, wide spread severe } \\
\text { impairment or loss of ecosystem functions, } \\
\text { public unrest, community unable to support } \\
\text { itself, long-term failure of service delivery } \\
\text { affecting all parts of community }\end{array}$} \\
\hline Extreme & $0 \%-5 \%$ & $\mathrm{RA}, \mathrm{TT}$ & Highly unlikely & Medium & Catastrophic & \\
\hline
\end{tabular}

a, See University of Vienna and National Directorate General for Disaster Management (2013).

GP, Godehoop; KA, Klein Australie; MA, Matiwa; NT, Nooitgedacht; PE, Palmaryville; RA, Rambuda; SA, Shefera; TT, Thathe, TS, Thakhuma; VB, Vondo Bos; ZS, Zwartrandjes; -, no years fell within SPI category.

drought will be. Although these events have lower probabilities of occurrence, their impacts are catastrophic and persist for a long period after the occurrence of the events. Thus, it would take long for communities to recover from such events. Unlike flood, drought will not cause destruction to infrastructure and household products. Rather, drought will affect water-depended services, including agriculture, industries and household water. The effects of drought result in high food prices, contribute to food insecurity and a negative impact on the economy of an area. Maponya and Mpandeli (2012) also reported that consequences of drought in Limpopo province include reduced grazing and water for livestock and irrigation and hence resulting in food scarcity. The latter study noted that farmers also sell their livestock to cope with reduced availability and higher prices of livestock feed during drought.

Catastrophic CLs were found in stations KA, MA, PE, TS, TA, VB and ZS (20 and $50 \mathrm{Tr}$ ), which are unlikely to occur or have very low chances of occurrence ( $2 \%$ probability) (Tables 4 and 8). Stations RA and TV had catastrophic CLs that are highly unlikely to occur within 20 and 50 years Tr. The latter CL can lead to severe water shortages that can result in imposition of water rationing. Major, moderate and minor CLs affect water resources availability at a rate less than the catastrophic CLs. Minor CL has the least impact on both the environment and communities.

The risk levels for drought categories vary from medium to high (Table 8). Risk level categories determine whether the risk treatment measures are required. Thus, medium to high risks call for the implementation of drought mitigation measures in the study area. Mpandeli (2014) reported that small-scale farmers in Vhembe District use different drought adaptive strategies, including drought-resistant varieties, crop diversification, plant crops that require less water, use local climate indicators to monitor climate risk, adjust fertiliser input and apply rainwater harvesting techniques. Drought relief programmes are implemented to combat water shortages in South Africa, including the study area, during drought periods. This includes drilling a number of emergency boreholes for groundwater supply, and rehabilitation and refurbishment of existing boreholes. These programmes were implemented during the 1992-1993 and 2015-2016 (Department of Water and Sanitation 2016) droughts, for example.

\section{Conclusions}

This study determined the hydrological hazards as well as the risks and vulnerabilities associated with these hazards. Annual daily maximum streamflow series was successfully fitted to an LP3 distribution for a period between 39 and 55 years. Mild dryness condition dominated the dry years in all stations with a range of $22.4 \%$ to $59.2 \%$ of the years falling within this category. Rainfall and streamflow showed both negative and positive trends, thus displaying their highly variable nature in the study area. The study generally shows that flood events are mostly associated with serious, significant and catastrophic CLs in the study area, making it highly prone to flood impacts such as loss of lives and damages to infrastructure. Additionally, CLs of different flood magnitudes have been determined in the VDM that had not been done before. The study also showed that communities in the study area are vulnerable to mild and moderate dryness conditions, which are associated with minor and moderate, and major impacts, respectively. Thus, there is high risk and vulnerability of communities to these hazards. The findings will aid in strategic mitigation of hydrological hazards in the study area.

\section{Acknowledgements}

This paper was presented at the first National Conference on Disaster Risk Science and Management in 'South Africa's Response in a changing global environment', 02-04 March 2015, at the Ranch Resort, Polokwane, South Africa. Jointly hosted by the University of Venda, School of Environmental Sciences, South Africa, and National Disaster Management 
Centre (representing Department of Cooperative Governance), South Africa. Faculty collaborators: Mr Tendayi Gondo, Prof. Agnes Musyoki and Mr Edmore Kori.

The authors hereby acknowledge Department of Water and Sanitation and South Africa Weather Service for providing data used in this study. The organisers of the Disaster Management Conference at the University of Venda where the paper was originally presented, 02 March 2015, are also acknowledged. The Directorate of Research and Innovation at the University of Venda is acknowledged for funding research retreat during the finalisation of the paper.

\section{Competing interests}

The authors declare that they have no financial or personal relationships which may have inappropriately influenced them in writing this article.

\section{Authors' contributions}

J.O. served as the project leader and conceptualised the idea, quality control of data analysis and paper writing. F.I.M. coordinated the paper writing and putting the paper together, as well as contributing scientifically in the flood frequency analysis and trend analysis sections. T.R.N. contributed to the flood risk and vulnerability section, and R.M. contributed to the drought frequency analysis and drought risk and vulnerability.

\section{Funding Information}

This research received no specific grant from any funding agency in the public, commercial, or not-for-profit sectors.

\section{Data availability statement}

Data sharing is not applicable to this article as no new data were created or analysed in this study.

\section{Disclaimer}

The views and opinions expressed in this article are those of the authors and do not necessarily reflect the official policy or position of any affiliated agency of the authors.

\section{References}

Alexander, W.J.R., 2001, Flood risk reduction measures, University of Pretoria Pretoria, South Africa.

Ayyub, B., 2003, 'Risk analysis methods', in Risk analysis in engineering and economics, p. 70-71, Chapman \& Hall, Boca Raton, FL.

Benjamin, M.A., 2008, 'Analysing urban flood risk in low-cost settlements of George, Western Cape, South Africa: Investigating physical and social dimensions', Masters dissertation, University of Cape Town.

Burn, D.H. \& Hesch, N.M., 2007, 'Trends in evaporation for the Canadian Prairies', Journal of Hydrology 336, 61-73. https://doi.org/10.1016/j.jhydrol. 2006.12.011

Cacciamani, C., Morgillo, A., Marchesi, S. \& Pavan, V., 2007, 'Monitoring and forecasting drought on a regional scale: Emilia-Romagna region', Water Science and Technology Library 62(1), 29-48. https://doi.org/10.1007/978-1-4020-5924-7_2

Department of Water Affairs, 2002, A proposed National Water Resources Strategy for South Africa, Proposed 1st edn., Department of Water Affairs and Forestry, Pretoria.
Department of Water and Sanitation, 2016, Drought status report no.4, DWS, Pretoria, South Africa.

Edossa, D.C., Woyessa, Y.E. \& Welderufael, W.A., 2014, 'Analysis of droughts in the central region of South Africa and their association with SST Anomalies', International Journal of Atmospheric Sciences 2014, Article ID 508953, 8 pages. https://doi.org/10.1155/2014/508953

Gbetibuou, G.A., 2009, Understanding farmers' perceptions and adaptations to climate change and variability: The case of the Limpopo Basin, South Africa, Discussion Paper', International Food Policy Research Institute, Washington, DC.

Glantz, M.H., Betsill, M. \& Crandall, K., 1997, Food security in Southern Africa: Assessing the use and value of ENSO information, National Oceanic and Atmospheric Administration, Silver Spring.

Goddard, W. \& Melville, S., 1996, Research methodology: An introduction, 2nd edn., Juta and Co Ltd., Cape Town.

Hamed, K.H., 2008, 'Trend detection in hydrologic data: The Mann-Kendall trend test under the scaling Hypothesis', Journal of Hydrology 349, 350-363. https://doi. org/10.1016/j.jhydrol.2007.11.009

Hirsh, R.M., Slack, J.R. \& Smith, R.A., 1982, 'Techniques of trend analysis for monthly water quality data', Water Resources Research 18(1), 107-121. https://doi. org/10.1029/WR018i001p00107

Hossain, M., 2014, 'Flood risk analysis in Ganges Basin', Bachelor's dissertation, Department of Civil Engineering, University of Asia Pacific.

International Federation's Disaster Relief Emergency Fund, 2011, South Africa: Floods, DREF operation $n^{\circ}$ MDRZA005 GLIDE $n^{\circ}$ FL-2011-000007-ZAF, viewed 01 February 2011, from http://www.ifrc.org/docs/appeals/11/MDRZA005.pdf.

Karmeshu, N., 2012, 'Trend detection in annual temperature \& precipitation using the Mann Kendall test - A case study to assess climate change on select states in the North-eastern United States', Master's thesis, Department of Earth \& Environmental Science, University of Pennsylvania.

Karlsson, P.O. \& Haimes, Y.Y., 1988, 'Risk-based analysis of extreme events', Water Resources Research 24(1), 9-20. https://doi.org/10.1029/WR024i001p00009

Kendall, M.G., 1975, Rank correlation methods, Griffin, London.

Kendall, M.G. \& Gibson, J.D., 1990, Rank correlation methods, A Charles Griffin Title, 5 th edn., Edward Arnold, London.

Limpopo Economic Development, Environment and Tourism (LEDET), 2015, Limpopo environmental outlook report, 1st Draft, viewed from www.ecoafrica.co.za/ limpopoEO.

Lindesay, J.A. \& Vogel C.H., 1990, 'Historical evidence for Southern Oscillationsouthern African rainfall relationships', International Journal of Climatology 10 679-689. https://doi.org/10.1002/joc.3370100703

Longobardi, A. \& Villani, P., 2009, 'Trend analysis of annual and seasonal rainfall time series in the Mediterranean area', International Journal of Climatology 30 1538-1546. https://doi.org/10.1002/joc.2001

MacKellar, N., New, M. \& Jack, C., 2014, 'Observed and modelled trends in rainfall and temperature for South Africa: 1960-2010', South African Journal of Science 110(7/8), 13. https://doi.org/10.1590/sajs.2014/20130353

Mann, H.B., 1945, 'Non-parametric test against trend', Econometrica 13, 245-259. https://doi.org/10.2307/1907187

Maponya, P. \& Mpandeli, S., 2012, 'Impact of drought on food scarcity in Limpopo province, South Africa', African Journal of Agricultural Research 7(37), 5270-5277. https://doi.org/10.5897/AJAR12.1453

McKee, T.B., Doesken, N.J. \& Kleist, J., 1993, 'The relationship of drought frequency and duration to time scales', Proceedings of the Eighth Conference on Applied Climatology, Anaheim, California, January 17-22, 1993, pp. 179-184.

Merz, B., Elmer, F. \& Thieken, A.H., 2009, 'Significance of "high probability/ low damage" versus "low probability/high damage" flood events', Natural Hazards and Earth System Sciences 9, 1033-1046. https://doi.org/10.5194/ nhess-9-1033-2009

Millington, N., Das, S. \& Simonovic, S.P., 2011, The comparison of GEV, Log-Pearson Type 3 and Gumbel distributions in the Upper Thames River Watershed under global climate models, Water Resources Research Report 077, University of Western Ontario, Ontario.

Moolchan, E., 2010, The impact of the 2007 Hurricane season operations for Trinidad and Tobago, Trinidad and Tobago Meteorological services, Piarco.

Mpandeli, N.S., 2014, 'Climate risks using seasonal climate forecast information in Vhembe District in Limpopo Province, South Africa', Journal of Sustainable Development 7(5), 68-81. https://doi.org/10.5539/jsd.v7n5p68

Mulugeta, G., Ayonghe, S., Daby, D., Dube, O.P., Gudyanga, F., Lucio, F. et al., 2007, 'Natural and human-induced hazards and disasters in sub-Saharan Africa', p. 30 ICSU Regional Office for Africa, Pretoria.

Musyoki, A., Thifhufhelwi, R. \& Murungweni, F.M., 2016, 'The impact of and responses to flooding in Thulamela Municipality, Limpopo Province, South Africa', Jàmbá: Journal of Disaster Risk Studies 8(2), a166. https://doi.org/10.4102/jamba. v8i2.166

Nenwiini, S. \& Kabanda, T.A., 2013, 'Trends and variability assessment of rainfall in Vhembe South Africa', Journal of Human Ecology 42(2), 171-176. https://doi.org/ 10.1080/09709274.2013.11906591

Nury, A.H., Koch, M. \& Alam, J.B., 2014, 'Analysis and prediction of time series variations of rainfall in North-Eastern Bangladesh', British Journal of Applied Science and Technology 4(11), 1644-1656. https://doi.org/10.9734/BJAST/2014/7722 
Oberg, K.A. \& Mades, D.M., 1987, Estimating generalized skew of the Log-Pearson Type III distribution for annual peak floods in Illinois, USGS, Water Resources Division, Reston.

Odiyo, J.O., Makungo, R. \& Nkuna, T.R., 2015, 'Long-term changes and variability in rainfall and streamflow in Luvuvhu River Catchment, South Africa', South African Journal of Science 111(7/8), 9. https://doi.org/10.17159/sajs.2015/ 20140169

Owemoje, T.A. \& Owemooje, O.S., 2011, 'Best distribution and plotting positions of daily maximum flood estimation at Ona River in Ogun-Oshun river basin, Nigeria', Agricultural Engineering International: The CIGR Journal 13(3), 11.

Rouault, M. \& Richard, Y., 2003, 'Intensity and spatial extension of drought in South Africa at different time scales', Water SA 29, 489-500. https://doi.org/10.4314/ wsa.v29i4.5057

Santhi, C.J.G., Arnold, J.R., Williams, W.A., Dugas, Srinivasan, R. \& Hauck, L.M., 2001 'Validation of the SWAT model on a large river basin with point and nonpoint sources', Journal of American Water Resources Association 37(5), 1169-1188. https://doi.org/10.1111/j.1752-1688.2001.tb03630.x

Singo, L.R., Kundu, P.M., Odiyo, J.O., Mathivha, F.I. \& Nkuna, T.R., 2012, 'Flood frequency analysis of annual maximum stream flows for Luvuvhu River Catchment, Limpopo Province, South Africa', in Proceedings of the 16th SANCIAHS Hydrology Symposium, Pretoria, South Africa, October 01-03, 2012, n.p.

Sutton, D.G. \& Kempi, V., 1993, 'Constrained least-squares restoration and renogram deconvolution: A comparison with other techniques', Physics in Medicine \& Biology 38(8), n.p. https://doi.org/10.1088/0031-9155/38/8/003
Unganai, L.S., 1994, 'Drought and Southern Africa: A note from the Harare Regional Drought Monitoring Centre', Drought Network News, viewed 24 May 2016, from http://digitalcommons.unl.edu/droughtnetnews/85.

University of Vienna (UV) and National Directorate General for Disaster Management (NDGDM), 2013, SEERISK: Common risk assessment methodology for the Danube macro-region, SEER!SK, Budapest.

Van Liew, M.W., Arnold, J.G. \& Garbrecht, J.D., 2003, 'Hydrologic simulation on agricultural watersheds: Choosing between two models', Transactions of the ASABE 46(6), 1539-1551. https://doi.org/10.13031/2013.15643

Vhembe District Municipality (VDM), 2011, Integrated development plan, viewed 16 April 2016, from http:www.limdhlgh.gov.za/documents/idp/.

Vogel, C.H., 1995, 'People and drought in South Africa: Reaction and mitigation', in T. Binns (eds.), People and environment in Africa, pp. 249-256, Wiley, West Sussex.

Vogel, C.H., Laing, M. \& Monnik, K., 2000, 'Drought in South Africa, with special reference to the 1980-94 period', in D.A. Wilhite (ed.), Drought volume 2 A global assessment, pp. 348-367, Routledge, London.

Water Research Commission (WRC), 2001, 'State of rivers report, Letaba and Luvuvhu River systems', WRC Report no. TT 165/01, Water Research Commission, Pretoria, South Africa.

Wilhite, D.A., Sivakumar, M.V.K. \& Pulwarty, R., 2014, 'Managing drought risk in a changing climate: The role of national drought policy', Weather and Climate Extremes 3, 4-13.

World Meteorological Organization (WMO), 2012, Standardized precipitation index user guide, WMO-No. 1090, Geneva, Switzerland. 